\title{
Engineering oleaginous yeast Rhodotorula toruloides for overproduction of fatty acid ethyl esters
}

Yang Zhang ${ }^{1+}$, Jie Peng ${ }^{1 \dagger}$, Huimin Zhao ${ }^{2^{*}}$ and Shuobo Shi ${ }^{{ }^{*}}$ (D)

\begin{abstract}
Background: Production of biofuels and green chemicals by microbes is currently of great interest due to the increasingly limited reserves of fossil fuels. Biodiesel, especially fatty acid ethyl esters (FAEEs), is considered as an attractive alternative because of its similarity with petrodiesel and compatibility with existing infrastructures. Cost-efficient bio-production of FAEEs requires a highly lipogenic production host that is suitable for large-scale fermentation. As a non-model oleaginous yeast that can be cultured to an extremely high cell density and accumulate over $70 \%$ cell mass as lipids, Rhodotorula toruloides represents an attractive host for FAEEs production.

Results: We first constructed the FAEE biosynthetic pathways in $R$. toruloides by introducing various wax ester synthase genes from different sources, and the bifunctional wax ester synthase/acyl-CoA-diacyglycerol acyltransferase (WS/DGAT) gene from Acinetobacter baylyi was successfully expressed, leading to a production of $826 \mathrm{mg} / \mathrm{L}$ FAEEs through shake-flask cultivation. We then mutated this bifunctional enzyme to abolish the DGAT activity, and further improved the titer to $1.02 \mathrm{~g} / \mathrm{L}$. Finally, to elevate the performance of $\triangle k u 70-A b W S^{*}$ in a bioreactor, both batch and fed-batch cultivation strategies were performed. The FAEEs titer, productivity and yield were $4.03 \mathrm{~g} / \mathrm{L}, 69.5 \mathrm{mg} / \mathrm{L} / \mathrm{h}$ and $57.9 \mathrm{mg} / \mathrm{g}$ (mg FAEEs/g glucose) under batch cultivation, and $9.97 \mathrm{~g} / \mathrm{L}, 90.6 \mathrm{mg} / \mathrm{L} / \mathrm{h}$, and $86.1 \mathrm{mg} / \mathrm{g}$ under fedbatch cultivation. It is worth mentioning that most of the produced FAEEs were secreted out of the cell, which should greatly reduce the cost of downstream processing.

Conclusion: We achieved the highest FAEEs production in yeast with a final titer of $9.97 \mathrm{~g} / \mathrm{L}$ and demonstrated that the engineered $R$. toruloides has the potential to serve as a platform strain for efficient production of fatty acid-derived molecules.
\end{abstract}

Keywords: Fatty acid ethyl esters, Wax ester synthase, R. toruloides, Enzyme engineering, Biodiesel, Metabolic engineering

\footnotetext{
*Correspondence: zhao5@illinois.edu; shishuobo@mail.buct.edu.cn

†Yang Zhang and Jie Peng contributed equally to this work

${ }^{1}$ Beijing Advanced Innovation Center for Soft Matter Science and Engineering, College of Life Science and Technology, Beijing

University of Chemical Technology, Beijing 100029, China

2 Department of Chemical and Biomolecular Engineering, University

of Illinois At Urbana-Champaign, Urbana, IL 61801, USA
}

\section{Background}

The global energy demand and environmental concerns have attracted worldwide attention to green and sustainable energy sources [1]. As one of the most promising alternative energy sources, biodiesel has high energy density, and is compatible with current infrastructure [2]. Moreover, it showed several advantages over petrodiesel, such as higher lubricity, and lower tailpipe emissions [3, 4]. Biodiesel consists of long-chain alkyl esters, mainly fatty acid methyl esters (FAMEs) and fatty acid ethyl

(C) The Author(s) 2021. This article is licensed under a Creative Commons Attribution 4.0 International License, which permits use, sharing, adaptation, distribution and reproduction in any medium or format, as long as you give appropriate credit to the original author(s) and the source, provide a link to the Creative Commons licence, and indicate if changes were made. The images or other third party material in this article are included in the article's Creative Commons licence, unless indicated otherwise in a credit line to the material. If material is not included in the article's Creative Commons licence and your intended use is not permitted by statutory regulation or exceeds the permitted use, you will need to obtain permission directly from the copyright holder. To view a copy of this licence, visit http://creativeco mmons.org/licenses/by/4.0/. The Creative Commons Public Domain Dedication waiver (http://creativecommons.org/publicdomain/ zero/1.0/) applies to the data made available in this article, unless otherwise stated in a credit line to the data. 
esters (FAEEs) [5]. Currently, commercial strategies for biodiesel production mainly use plant oils or animal fats as feedstock to produce FAMEs through chemical transesterification [6, 7]. However, these strategies compete for lands and materials required for food production and also cause environmental problems [2, 8]. Therefore, it is desirable to use renewable plant biomass as a feedstock to produce FAEEs by microbial fermentation [9].

Over the past decades, various microbial hosts such as Escherichia coli, Saccharomyces cerevisiae, and Yarrowia lipolytica have been engineered to produce FAEEs. In E. coli, the production of FAEEs was achieved by heterologously expressing genes encoding the pyruvate decarboxylase (PDC), alcohol dehydrogenase (ADH), and wax ester synthase/acyl-CoA-diacyglycerol acyltransferase (WS/DGAT) gene from $A$. baylyi [5]. The maximum FAEEs titer reached $19 \mathrm{~g} / \mathrm{L}$ by adding exogenous oleic acids in fed-batch pilot-scale fermentation [10]. Röttig and coworkers showed that use of a mutant AbWS from A. baylyi (Ile355Gly) led to a higher FAEEs titer than the wild-type AbWS in E. coli [11]. In S. cerevisiae, Shi and coworkers constructed a similar FAEE biosynthetic pathway and demonstrated the WS from Marinobacter hydrocarbonsticus led to the highest FAEEs titer of $6.3 \mathrm{mg} / \mathrm{L}$ [12]. Later, Yu and coworkers improved the titer to $0.52 \mathrm{~g} / \mathrm{L}$ FAEEs by adding exogenous fatty acids [13]. In both $E$. coli and $S$. cerevisiae, the production of FAEEs was regarded to be limited by the supply of lipid precursors, and the addition of exogenous oleic acids can improve the final titer significantly $[10,13]$, which suggests that use of host strains with robust lipid producing capacity such as oleaginous yeasts may be advantageous. Indeed, $\mathrm{Xu}$ and coworkers engineered a representative oleaginous yeast $Y$. lipolytica to produce FAEEs and found that the subcellular localization of WSs was essential for the production of FAEEs in the strain [14]. Cytosolic expression of WS from A. baylyi ADP1 only resulted in marginal production at $7.1 \mathrm{mg} / \mathrm{L}$, and when WS was targeted to the endoplasmic reticulum (ER), the FAEEs titer was improved significantly to $136.5 \mathrm{mg} / \mathrm{L}$. In a further study, Gao and coworkers revealed that the expression of WS from $M$. hydrocarbonsticus led to the highest FAEEs titer of $0.4 \mathrm{~g} / \mathrm{L}$ with additional exogenous ethanol, and through pathway optimization for supplying cytosolic acyl-CoA, the production titer reached $1.18 \mathrm{~g} / \mathrm{L}$ [15].

In addition to $Y$. lipolytica, $R$. toruloides is another promising oleaginous yeast. Compared with $Y$. lipolytica, $R$. toruloides produces a higher titer of lipids $[16,17]$, and can naturally utilize a variety of carbon sources derived from plants, including xylose and cellobiose [18], thereby exhibiting a broader industrial application prospect in the production of lipid-related products. However, metabolic engineering of $R$. toruloides was hindered by the lack of efficient genetic manipulation tools [16] [19], and only limited metabolic engineering efforts were reported [16, $18]$. To date, there is no report using this species to produce biodiesels using a metabolic engineering approach.

In the present study, we explored the potential of $R$. toruloides to produce FAEEs. Five WSs previously reported in S. cerevisiae were codon optimized and introduced to $R$. toruloides (Fig. 1) [12]. However, only the AbWS from $A$. baylyi was successfully expressed, and the recombinant strain successfully produced FAEEs by adding exogenous ethanol to the culture. Then, the AbWS was engineered to improve the production of FAEEs by abolishing its side activity. Finally, by carrying out fed-batch fermentation in a 1-L fermenter, the production reached a maximum of $9.97 \mathrm{~g} / \mathrm{L}$ FAEEs (including both extracellular and intracellular titers). To the best of our knowledge, this engineered cell factory possessed the highest FAEEs production levels in a yeast host. Notably, the FAEEs produced by $R$. toruloides were mainly secreted outside the

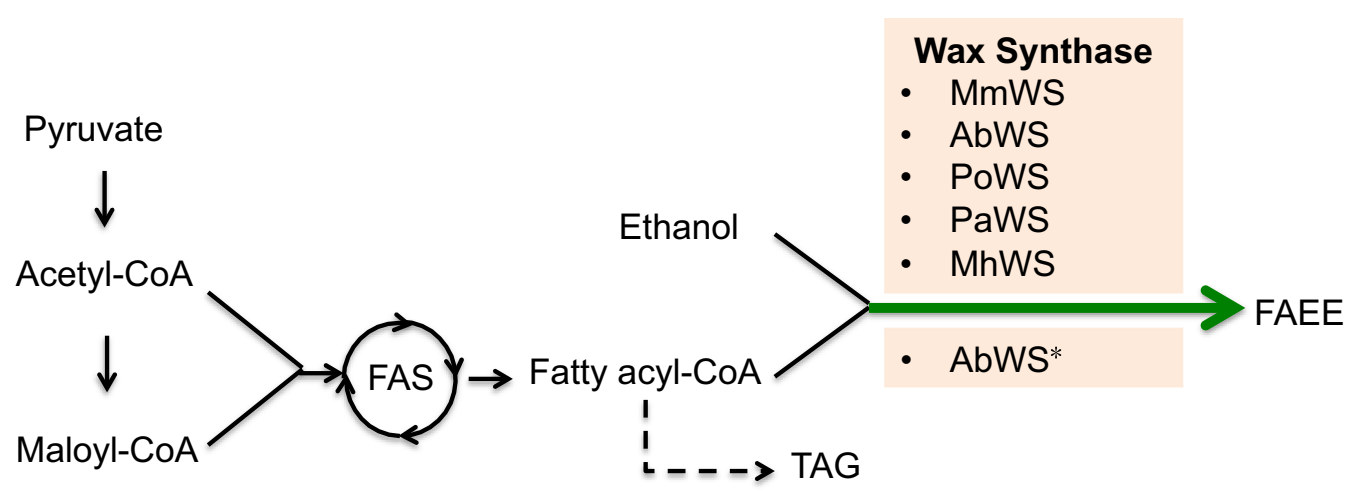

Fig. 1 Construction of the FAEE biosynthetic pathway by introducing WSs sourced from various organisms 
cell, which would greatly reduce the cost in the subsequent downstream processes.

\section{Results}

\section{Overexpression of WSs for FAEEs production in $R$.} toruloides

WS catalyzes esterification of fatty acyl coenzyme A (fatty acyl-CoA) with alcohols of various chain lengths for synthesizing fatty esters. WSs derived from different sources have a wide range of substrate preferences, leading to different catalytic efficiencies. When it is expressed in a heterologous host, the source of the enzyme is a key factor to affect the catalytic efficiency.

To compare the efficiency of various WSs in $R$. toruloides, five previously reported wax ester synthase genes [12] were selected and codon optimized. They were MhWS from M. hydrocarbonoclasticus DSM 8798 (GenBank ID: EF219377.1), AbWS from A. baylyi ADP1 (GenBank ID: AF529086), RoWS from Rhodococcus opacus PD630 (GenBank ID:GQ923886), MmWS from Mus musculus C57BL/6 (GenBank ID: AY611032), and PaWS from Psychrobacter arcticus 273-4 (GenBank ID: YP_263530). Additional file 1: Table S1 summarizes the application of these enzymes in S. cerevisiae and their specific enzyme activities for FAEE production.

To construct the recombinant plasmids, a Flag tag was added at the start of each gene and subcloned into plasmid pKOCAR2. The resulting plasmids were transformed to $R$. toruloides $\Delta k u 70$, yielding the recombinant strains named $\Delta k u 70-M h W S, \Delta k u 70$ AbWS, $\Delta k u 70-R o W S, \quad \Delta k u 70-M m W S$ and $\Delta k u 70-$ PaWS (Table 1). The expression of WSs was examined by Western blot method. It was found that only AbWS with a molecular weight of $53.78 \mathrm{kDa}$ was successfully expressed (Fig. 2a), with a band around $53 \mathrm{kDa}$ obtained. Therefore, the recombinant $\triangle k u 70-A b W S$ was used as the candidate for further research.

The strain was cultured in $10 \mathrm{~mL}$ fermentation medium in an orbital shaker at a rotary rate of $250 \mathrm{rpm}$ at $30{ }^{\circ} \mathrm{C}$. Since $R$. toruloides is unable to produce ethanol under laboratory conditions, exogenous ethanol was added to the culture medium. To minimize the inhibitory effect of ethanol, the strain was cultured by $8 \sim 12 \mathrm{~h}$ (OD600 reached to $\sim 2$ ) before feeding ethanol. To facilitate the extraction process, $10 \%$ dodecane was added to the culture as reported previously [15], and ethyl heptadecanoic was used as the internal standard. Extracellular FAEEs were extracted to the dodecane layer and detected by gas chromatography-mass spectrometry (GC-MS) (Fig. 2b). The composition of FAEEs produced by $\triangle k u 70-A b W S$ was mainly composed of ethyl myristic (C14:0), ethyl palmitic (C16:0), ethyl stearic (C18:0), ethyl oleic (C18:1), and ethyl linoleic (C18:2). The ratio of each component resembled that of total lipid in the same strain (Additional file 1: Fig. S1).

Table 1 Strains and plasmids used in this study

\begin{tabular}{|c|c|c|}
\hline Strains or plasmids & Relevant characteristics & Source or reference \\
\hline \multicolumn{3}{|l|}{ Strains } \\
\hline$\triangle k u>0$ & R. toruloides IFO0880 deficient in ku70 & [34] \\
\hline$\triangle k u 70-A b W S$ & $\triangle k u 70$ strain harboring the AbWS cassette & This study \\
\hline$\triangle k u 70-A b W S^{*}$ & $\triangle k u 70$ strain harboring the $A b W S^{*}$ cassette & This study \\
\hline$\triangle k u 70-M m W S$ & $\triangle k u 70$ strain harboring the MmWS cassette & This study \\
\hline$\triangle k u 70-M h W S$ & $\triangle k u 70$ strain harboring the MhWS cassette & This study \\
\hline$\triangle$ ku70-PaWs & $\triangle$ ku70 strain harboring the PaWS cassette & This study \\
\hline$\triangle$ ku70-RoWs & $\triangle$ ku70 strain harboring the RoWS cassette & This study \\
\hline AGL-1 & A. tumefaciens strain AGL0 recA::bla pTiBo542 $\triangle \mathrm{T} \mathrm{Mop}{ }^{+} \mathrm{CbR}$ & [15] \\
\hline $\mathrm{DH} 5 \mathrm{a}$ & E. coli (supE44 lacU169 hsdR17 recA1 endA1 gyrA96 thi-I relA1) & Laboratory storage \\
\hline \multicolumn{3}{|l|}{ Plasmids } \\
\hline PKOCAR2 & $\begin{array}{l}\text { Harboring the hygromycin selection cassette for target gene incorporation at the } \\
\text { specific site in CAR2 gene }\end{array}$ & [32] \\
\hline p101 & Harboring the MhWS cassette & This study \\
\hline p102 & Harboring the AbWS cassette & This study \\
\hline p103 & Harboring the RoWS cassette & This study \\
\hline p104 & Harboring the MmWS cassette & This study \\
\hline p105 & Harboring the PaWS cassette & This study \\
\hline p1022 & Harboring the AbWS* cassette & This study \\
\hline
\end{tabular}




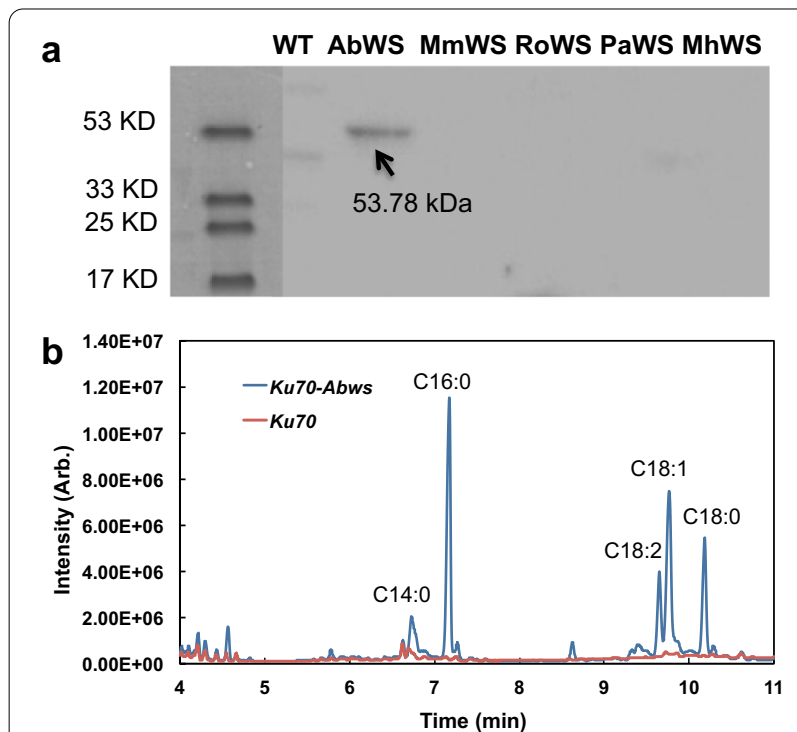

Fig. 2 Overexpression of wax synthase genes from different sources in $R$. toruloides. a Detection of protein expression by Western blot. "WT", "AbWS", "MmWS", "RoWS", "PaWS" and "MhWS" represent the protein samples extracted from $R$. toruloides $\triangle k u 70, \triangle k u 70-A b W S$, $\triangle k u 70-M m W S, \triangle k u 70-R o W S, \triangle k u 70-P a W S$ and $\triangle k u 70-M h W S$, respectively. $\mathbf{b}$ GC-MS analysis of the FAEEs produced in the recombinant $\triangle k u 70-A b W S$ strain (the blue line) and the parental strain R. toruloides $\triangle k u 70$ (the red line). The components of C14:0, C16:0, C18:0, C18:1 and C18:2 stand for ethyl myristic, ethyl palmitic, ethyl stearic, ethyl oleic, and ethyl linoleic, respectively

\section{Exploration of the optimal exogenous ethanol concentration for FAEEs production}

Although ethanol is required for FAEEs production, its toxicity may affect cell growth and lead to a decreased FAEEs yield. Therefore, we sought to determine an optimal ethanol concentration for both minimizing the substrate cost and maximizing the production titer. Ethanol was added to the medium at a final concentration of $8.0 \mathrm{~g} / \mathrm{L}(1 \%), 24.0 \mathrm{~g} / \mathrm{L}(3 \%), 40.0 \mathrm{~g} / \mathrm{L}(5 \%)$, and $56.0 \mathrm{~g} / \mathrm{L}$ (7\%), respectively. Figure 3a shows the effect of different ethanol concentrations on cell growth of the recombinant $\Delta k u 70-A b W S$ strain in shake-flask fermentation. As expected, ethanol had an inhibitory effect on cell growth. When the ethanol concentration was $1 \%$, the effect on cell growth was inconspicuous. But when the ethanol concentration was above $3 \%$, the effect on cell growth was significant. The addition of ethanol also had a similar effect on the final cell mass. Figure $3 \mathrm{~b}$ shows the effect of different ethanol concentrations on cell mass formation and glucose consumption. When the ethanol concentration was above $3 \%$, the final cell mass almost decreased by half, and the glucose consumption was significantly reduced.

We then measured the FAEE titer in shake flask cultivation. After culturing for $60 \mathrm{~h}$, the extracellular and

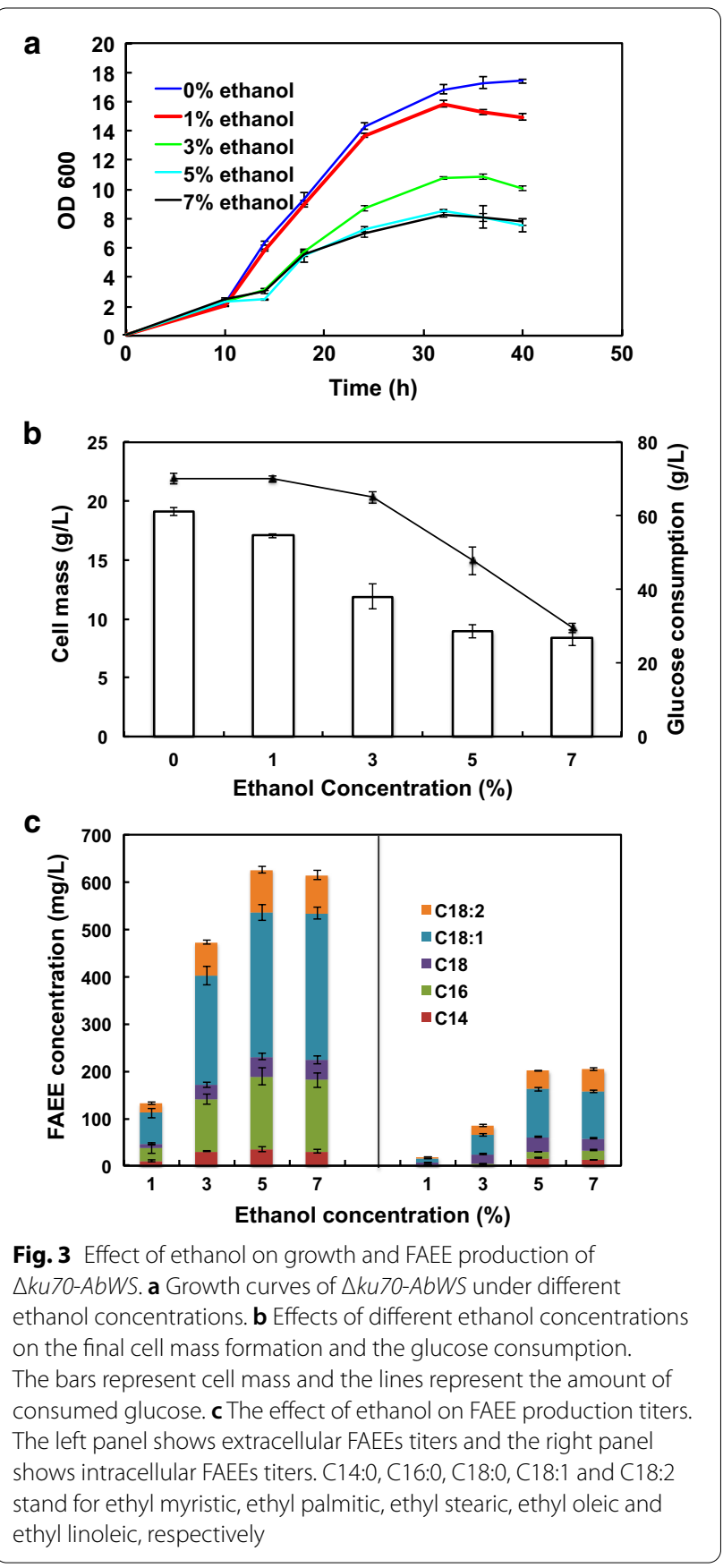

intracellular FAEEs were extracted by different methods, and the results are shown in Fig. 3c. When the ethanol concentration was $1 \%$ and $3 \%$, the extracellular FAEEs titers were significantly lower than that of $5 \%$ and $7 \%$. A similar trend was also noted for the production of intracellular lipids analyzed by thin layer chromatography (TLC) (Additional file 1: Fig. S2). When the ethanol concentration was $1 \%$ and $3 \%$, the fatty acid precursor was mainly stored in the triglycerides (TAG) form, and when 
the ethanol concentration rose to $5 \%$ and $7 \%$, most of the fatty acid precursor flowed to the synthesis of FAEEs. Taken together, the maximum FAEEs titer was $826 \mathrm{mg} / \mathrm{L}$, including $625 \mathrm{mg} / \mathrm{L}$ extracellular and $201 \mathrm{mg} / \mathrm{L}$ intracellular titers, under the $5 \%$ exogenous ethanol condition. When the ethanol concentration was further increased to $7 \%$, the FAEEs titer did not show a further increase. Thus, $5 \%$ is considered as the optimal ethanol concentration for FAEEs production. It is worth mentioning that the background strain $\Delta k u 70$ also appeared to produce a small amount of extracellular FAEEs after adding exogenous ethanol (Additional file 1: Fig. S3). This is possibly due to the existence of native lipases in the strain, which can catalyze the esterification process [20].

To further improve the FAEE titers, we also tried a nitrogen-limited medium $(70 \mathrm{~g} / \mathrm{L}$ glucose, $0.75 \mathrm{~g} / \mathrm{L}$ yeast extract, $1.7 \mathrm{~g} / \mathrm{L}$ yeast nitrogen base without amino acids and ammonium sulfate, and $0.1 \mathrm{~g} / \mathrm{L}\left(\mathrm{NH}_{4}\right)_{2} \mathrm{SO}_{4}, \mathrm{pH}$ 5.6) for shake-flask cultivation. The medium was reported to improve lipid content in $R$. toruloides [21]. However, the FAEE titer was lower than that in the fermentation medium (Additional file 1: Fig. S4). Thus, we used the fermentation medium for subsequent studies.

\section{Modification of the AbWS enzyme to improve the FAEEs production}

As reported previously, a point mutation of AbWS at residue 355 from glycine to isoleucine led to a shifted substrate selectivity toward shorter chain alcohols and an impaired DGAT activity [11]. Guided by this finding, we created the same mutant AbWS* (Fig. 4a) and introduced it to the $\Delta k u 70$ strain. To compare the efficiency with the wild-type AbWS, the AbWS* and AbWS expression cassettes were integrated in the same CAR2 site of the chromosome to reduce discrepancies caused by integration sites. Only white colonies were selected that indicated as a correct integration (Additional file 1: Fig. S5). Gene sequencing was used to further verify the integration site of the cassettes using the primers of UCar2F/DCar2R (Additional file 1: Table S2) that located in the upstream of Car2L and downstream of Car2R in the chromosome of $R$. toruloides, respectively.

To evaluate the performance of AbWS* and AbWS, the specific activity of the cell lysate was measured. It was found the highest activity of the AbWS* towards palmitoyl coenzyme A was $2.40 \pm 0.15 \mathrm{nmol} / \mathrm{mg} / \mathrm{min}$, and the highest activity of AbWS was $2.14 \pm 0.23 \mathrm{nmol} /$ $\mathrm{mg} / \mathrm{min}$. This result was consistent with previous studies $[11,22,23]$, which indicated that the point mutation did not improve the specific activity significantly, but rather altered its affinity to ethanol.

The performance of the $\Delta k u 70-A b W S^{*}$ was then tested by shake-flask fermentation. After culturing for $60 \mathrm{~h}$,

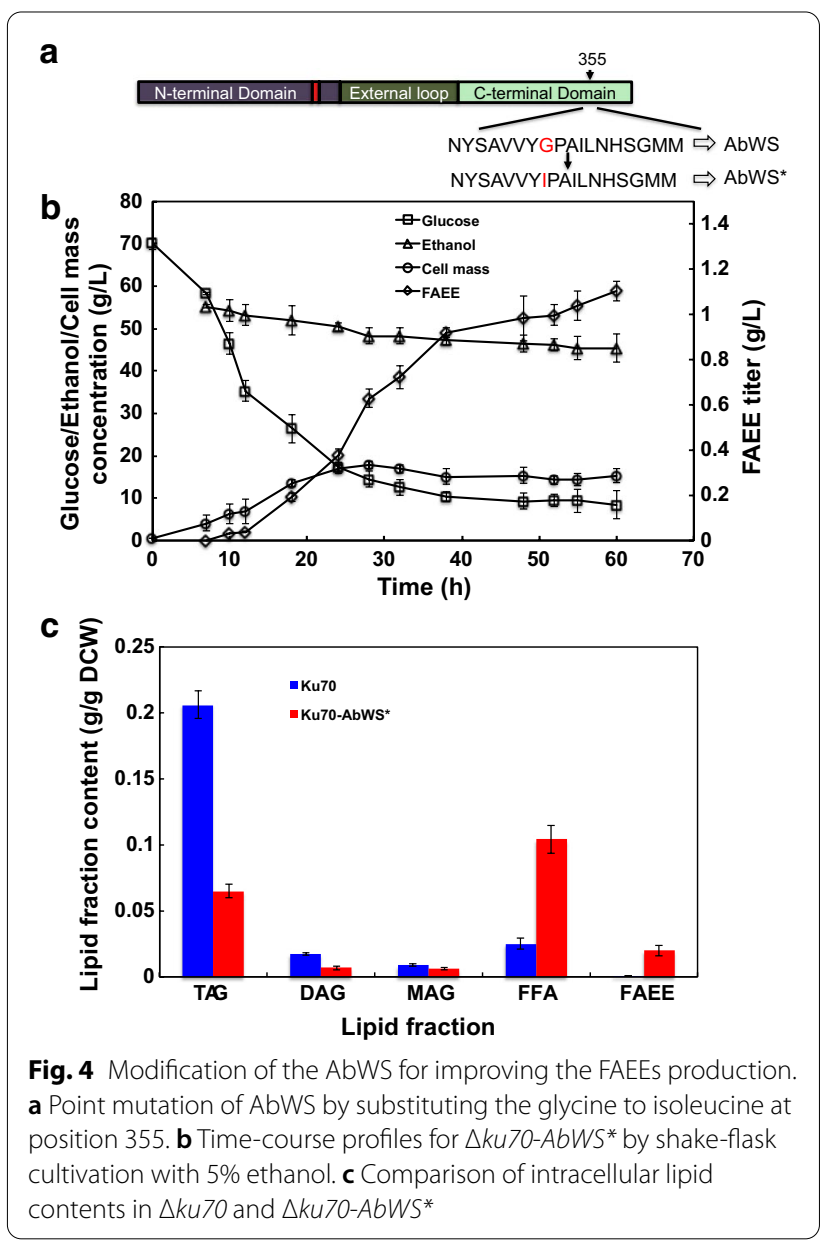

the extracellular and intracellular FAEEs were measured, respectively, and the production titers are shown in Additional file 1: Fig. S6. Compared with the wild-type AbWS, the mutant showed higher efficiency in producing FAEEs. The maximum FAEEs titer reached $1024 \mathrm{mg} / \mathrm{L}$ under the addition of $5 \%$ exogenous ethanol, including $810 \mathrm{mg} / \mathrm{L}$ extracellular and $214 \mathrm{mg} / \mathrm{L}$ intracellular titers. In addition, when ethanol concentration varied from 1 to $7 \%$, compared to $\Delta k u 70-A b W S$, the recombinant $\Delta k u 70$ $A b W S^{*}$ strain tended to synthesize more ethyl palmitic and less ethyl linoleic. Additional file 1: Fig. S7 displays the proportion of FAEE components under $5 \%$ ethanol concentration in both $\triangle k u 70-A b W S$ and $\triangle k u 70-A b W S^{*}$ strains. This result might indicate a preference of the AbWS* towards palmitoyl-CoA, although it has not been reported in previous studies.

To further investigate the production yield and productivity, the growth of the strain was monitored along the time course under $5 \%$ ethanol conditions. The concentrations of glucose, ethanol, cell mass and FAEE were determined by fermentation. As shown in Fig. 4b, the glucose was consumed by approximately $60 \mathrm{~g} / \mathrm{L}$, and the ethanol 
was decreased from $56 \mathrm{~g} / \mathrm{L}$ to $\sim 45 \mathrm{~g} / \mathrm{L}$ in $60 \mathrm{~h}$, with a maximum FAEEs titer of $1.10 \mathrm{~g} / \mathrm{L}$. The FAEE productivity and yield of FAEEs were $18.3 \mathrm{mg} / \mathrm{L} / \mathrm{h}$ and $17.9 \mathrm{mg} / \mathrm{g}$ glucose. We also monitored the ethanol reduction in a blank medium in an orbital shaker at a rotary rate of $250 \mathrm{rpm}$ at $30{ }^{\circ} \mathrm{C}$, and found that the ethanol concentration was decreased by $\sim 10 \mathrm{~g} / \mathrm{L}$ in $60 \mathrm{~h}$. In comparison, the ethanol concentration was decreased by $\sim 11 \mathrm{~g} / \mathrm{L}$ reduction of during the fermentation process (Fig. $4 \mathrm{~b}$ ). Thus, we considered the consumption of ethanol was mainly due to evaporation.

Both FAEE and TAG were biosynthesized from the fatty acyl-CoA precursor. The intracellular lipid contents of $\Delta k u 70$ and $\Delta k u 70-A b W S^{*}$ were measured after shake flask cultivation. As shown in Fig. 4c, in the parent $\triangle k u 70$ strain, the lipids were stored mainly in TAG form $(\sim 0.2 \mathrm{~g} / \mathrm{g}$ DCW $)$, while in $\Delta k u 70-A b W S^{*}$, the TAG contents decreased significantly $(\sim 0.06 \mathrm{~g} / \mathrm{g} \mathrm{DCW})$, and the intracellular FAEEs increased greatly. To our surprise, the FFAs in the recombinant strain was also increased, indicating the expression of AbWS may induce the decomposition of TAG.

\section{Overproduction of FAEEs during high-density cultures using bioreactors}

To evaluate its performance in a bioreactor, we cultivated the $\Delta k u 70-A b W S^{*}$ strain in a 1-L bioreactor under aerobic batch (Fig. 5a) and fed-batch (Fig. 5b) conditions, respectively. The concentrations of glucose, ethanol, FAEEs and cell mass were all monitored over time.

We first tested the performance of $\Delta k u 70-A b W S^{*}$ through batch cultivation. The initial glucose concentration was $70 \mathrm{~g} / \mathrm{L}$, and the medium was inoculated with $10 \%$ seed culture. As shown in Fig. 5a, when the fermentation was finished at $58 \mathrm{~h}$, there was a total consumption of $\sim 10 \mathrm{~g} / \mathrm{L}$ ethanol, and the final titer, productivity and yield of FAEEs were $4.03 \pm 0.11 \mathrm{~g} / \mathrm{L}$ (including an intracellular titer of $0.52 \mathrm{~g} / \mathrm{L}), 69.5 \mathrm{mg} / \mathrm{L} / \mathrm{h}$, and $57.9 \mathrm{mg} / \mathrm{g}$ (g FAEEs produced/g glucose consumed), respectively. Compared with shake-flask batch fermentation, the FAEEs titer was significantly improved in the bioreactor, and this may be benefited from the continuous ventilation and the appropriate $\mathrm{pH}$ in the bioreactor. In addition, the pattern of feeding ethanol may also contribute to the higher titer of FAEEs because the ethanol was pumped to the bioreactor, which may decrease the toxic effect to the cells.

To further improve the FAEE production, a fed-batch strategy was employed. As shown in Fig. 5b, after culturing for $32 \mathrm{~h}$, the glucose concentration was decreased to $14 \mathrm{~g} / \mathrm{L}$. To avoid carbon limitation, additional glucose was fed to the $500 \mathrm{~mL}$ medium in the bioreactor, leading to a concentration of $64 \mathrm{~g} / \mathrm{L}$. When the fermentation was finished at $110 \mathrm{~h}$, there was a total consumption of $\sim 17 \mathrm{~g} / \mathrm{L}$ ethanol, and the final FAEEs titer reached a maximum of $9.97 \mathrm{~g} / \mathrm{L}$ (including $1.3 \mathrm{~g} / \mathrm{L}$ intracellular titers). The productivity was $90.6 \mathrm{mg} / \mathrm{L} / \mathrm{h}$, and the production yield was $86.1 \mathrm{mg} / \mathrm{g}$.

To know whether there are any TAGs left in the cell mass, the lipid content was measured after batch and fed-batch cultivation. The data are shown in Additional file 1: Table S3. The result indicated that limited amounts of TAGs were detected in the intracellular lipids. Thus, we demonstrate that the $\triangle k u 70-A b W S^{*}$ is a robust FAEE producing platform with strong wax ester synthase activity.

\section{Discussion}

Biodiesel can contribute significantly to the development of sustainable transportation fuels in the future [1], and biotechnology provides an alternative process, where the biodiesel can be produced from abundant biomass feedstocks using microorganisms. $R$. toruloides, a nonmodel oleaginous yeast, is an ideal organism to produce biodiesel because of its robust ability to accumulate single cell oils (SCOs) and capability to utilize various carbon sources [16]. Previously, this organism was used to produce biodiesel esters consisting of FAMEs through a "microbial oil process", which involves the production of bio-oil by microbial cells and an additional transesterification reaction [24]. Moreover, a whole-cell catalyst technology was reported to convert $73 \%$ total lipids into FAEEs in the strain [20]. However, the catalytic mechanism was unclear and it was only hypothesized that the lipases on the membrane of lipid droplets might play an important role in the synthesis of FAEEs. All these reported processes had to lyse the cells for lipids extraction, which increased the production costs.

Recently, the emerging use of WSs highlighted the rational construction of microbial cell factories for directly producing FAEEs by fermentation in various hosts $[5,10-15,25]$. Inspired by these studies, we engineered a recombinant $R$. toruloides strain $\triangle k u 70-A b W S^{*}$ capable of directly producing FAEEs by fermentation. Compared with the previous studies [20, 24], which needed to separate the oil-accumulation and the esterification processes, the strategy reported here synchronized such two courses, thus avoiding additional esterification procedure. Moreover, it will be accessible to control the synthesis of FAEEs through metabolic engineering, which is not available in previous reports [20,24].

Through fed-batch fermentation in a 1-L fermenter, we obtained a maximal FAEEs production of $9.97 \mathrm{~g} / \mathrm{L}$. This is to date the highest production titer in any yeast including the commonly used oleaginous yeast $Y$. lipolytica [15]. It is worth mentioning that the FAEEs produced by 


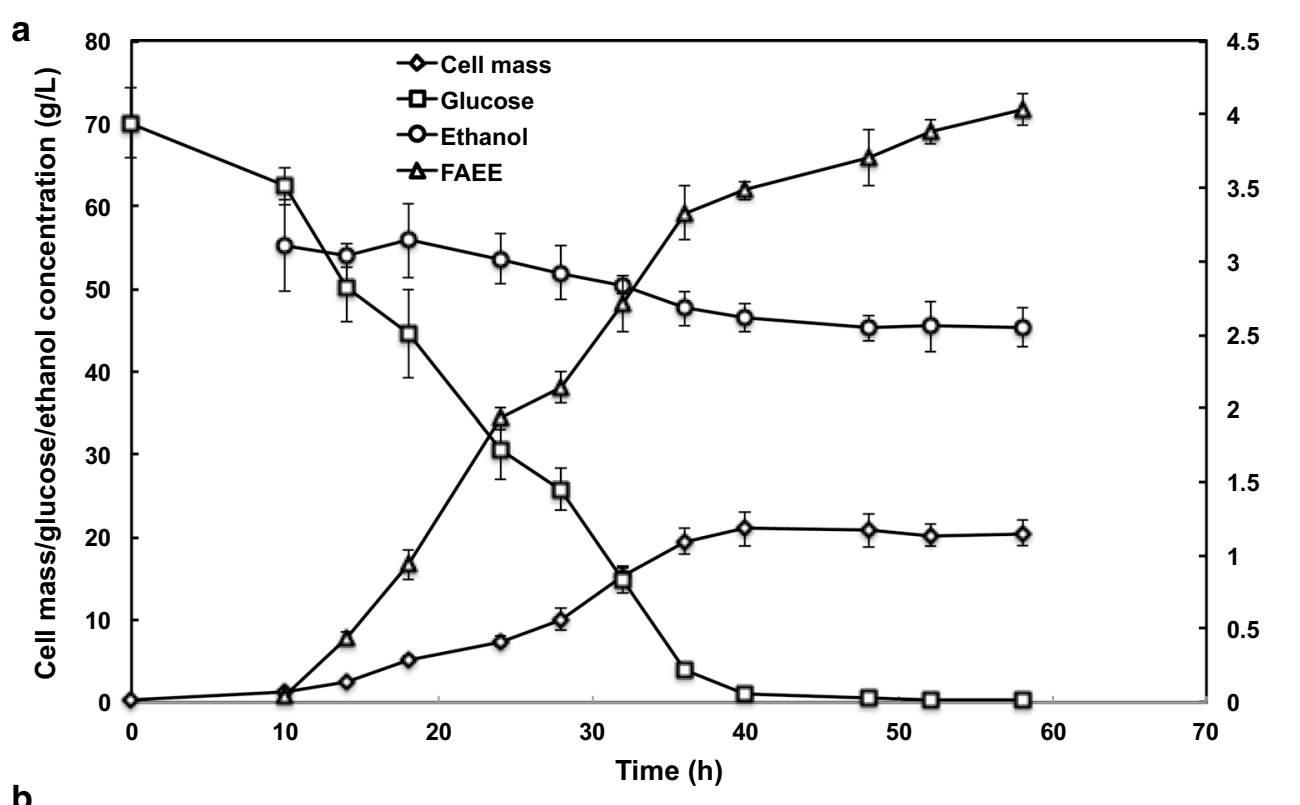

b

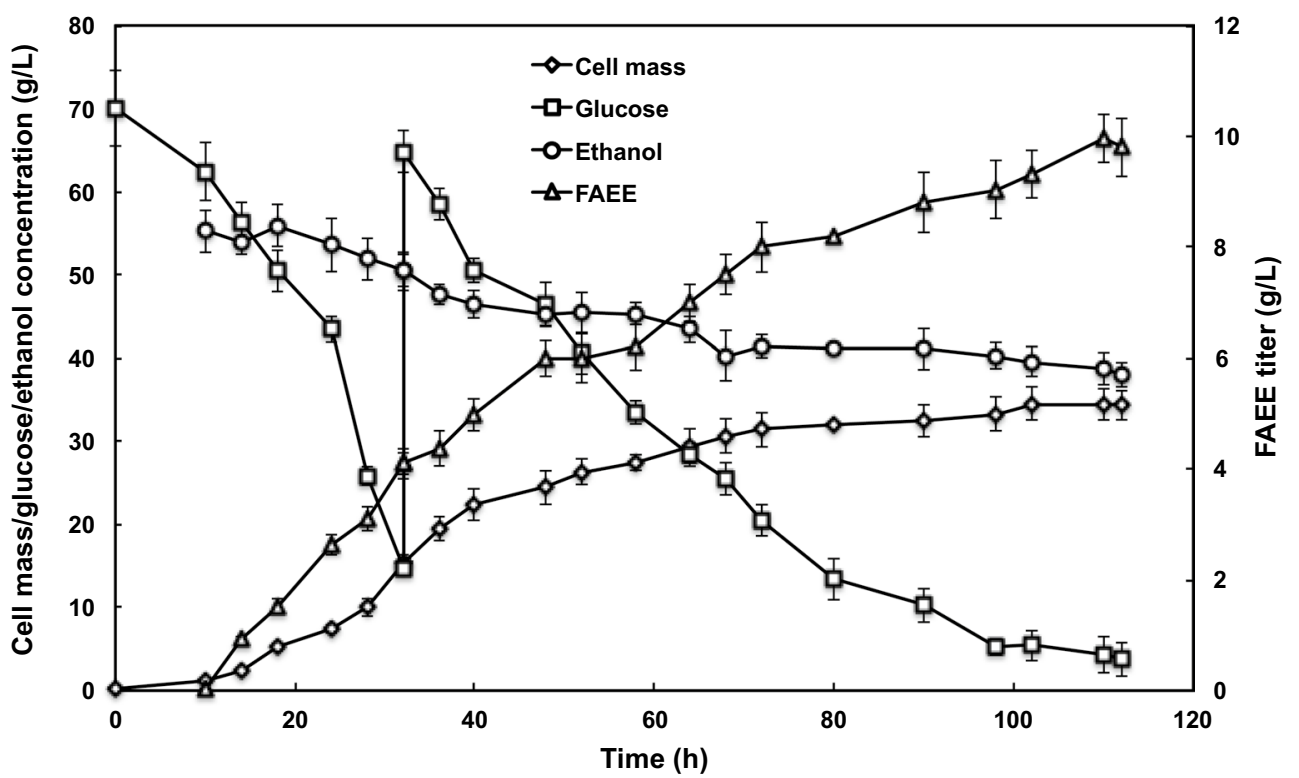

Fig. 5 Time-course profiles for batch (a) and fed batch (b) cultivation of R. toruloides. Empty square, glucose concentration; black diamond, cell mass; empty triangle, FAEE concentration; black circle, ethanol

the engineered strain were mainly secreted outside the cell $(8.6 \mathrm{~g} / \mathrm{L}$ extracellular FAEEs were obtained). This is possibly due to its ability to assimilate hydrophobic carbon sources as substrates using an unknown transport system [16], which can work bidirectionally to secrete the product of FAEEs. For example, the transporter FATP1 can not only assimilate fatty acids, but also work as a fatty acid exporter [26]. The secretion may greatly reduce the production cost by avoiding product extraction as reported in S. cerevisiae [12, 13, 27]. Therefore, the engineered cell factory serves as a potential platform for the industrial production of FAEEs. In the future, genetic manipulation strategies such as overexpressing genes related to acetyl-CoA accumulation and eliminating competing pathways (peroxisome $\beta$-oxidation and TAG biosynthesis) are expected to further improve the production level.

While we have demonstrated that $R$. toruloides has great potential for large-scale production of biodiesels during this study, a major bottleneck to implement an 
economically feasible process is the additional cost associated with providing exogenous ethanol. Although it was reported that $R$. toruloides contained ethanol synthesis genes encoding PDC and ADH [28], it failed to produce ethanol under current experimental conditions (data not shown). Also there has been no report that $R$. toruloides has the ability to produce ethanol. To avoid the need to feed ethanol, two heterologous genes that encode PDC1 [29] and ADH4 [30] from S. cerevisiae were introduced to $R$. toruloides $\Delta k u 70$, with an aim to create an aerobic ethanol biosynthetic pathway. Unfortunately, the two corresponding enzymes could not be solubly expressed in the engineered strain based on Western blot (data not shown). In the future, more ethanol biosynthetic pathway genes from different ethanologenic organisms need to be evaluated and introduced to our engineered $R$. toruloides strain to construct an endogenously ethanol-producing pathway. Recently, this proposed strategy was demonstrated to be feasible in the oleaginous yeast $Y$. lipolytica for the synthesis of FAEEs without the addition of ethanol, but the titer of produced FAEEs was quite low $(0.3 \mathrm{mg} / \mathrm{L})$ due to the limited supply of ethanol [31]. Thus, further efforts to increase the production of ethanol is required. If successful, it will greatly promote the industrial development of biodiesel synthesis in the oleaginous yeasts.

\section{Conclusions}

In this study, $R$. toruloides was engineered to produce FAEEs by fermentation for the first time by heterologously expressing the WS from A. baylyi ADP1. The optimal ethanol concentration for FAEEs production was proved to be $5 \%$, which led to a maximum FAEEs titer of $0.82 \mathrm{~g} / \mathrm{L}$. To further improve the FAEEs production, the AbWS enzyme was modified by site-directed mutagenesis to change its substrate preferences, which significantly increased the production titer to $1.02 \mathrm{~g} / \mathrm{L}$. Finally, by carrying out fed-batch fermentation in a 1-L fermenter, the engineered strain was able to produce FAEEs up to a titer of $9.97 \mathrm{~g} / \mathrm{L}$. This is to date the highest FAEEs production level in a yeast host. Furthermore, the FAEEs produced by the strain were mainly secreted outside the cell, which can greatly save the costs for FAEE extraction. Overall, $R$. toruloides has the potential to become an excellent platform organism for industrial production of biodiesels and other fatty acid-derived green fuels or chemicals.

\section{Methods}

\section{Strains and media}

The parent strain in this study was $R$. toruloides $\Delta k u 70$, a derivative of $R$. toruloides IFO0880 with a deletion in the non-homologous end joining (NHEJ) gene, ku70 [32]. Agrobacterium tumefaciens AGL-1 strain was used for transformation experiments $[18,33]$. The E. coli $\mathrm{DH} 5 \alpha$ was used for plasmid construction.

$R$. toruloides strains were routinely grown in liquid or solid yeast extract-peptone-dextrose (YPD) medium $(10 \mathrm{~g} / \mathrm{L}$ of yeast extract, $20 \mathrm{~g} / \mathrm{L}$ of peptone, $20 \mathrm{~g} / \mathrm{L}$ glucose) at $30{ }^{\circ} \mathrm{C}$ for strain construction and activation, and in fermentation medium (glucose $70.0 \mathrm{~g} / \mathrm{L}$, peptone $15.7 \mathrm{~g} / \mathrm{L}$, yeast extract $15.7 \mathrm{~g} / \mathrm{L}$ ) for both shake-flask batch fermentation and bioreactor fed-batch fermentation. E. coli strains were routine grown in Luria-Bertani broth (LB) medium at $37^{\circ} \mathrm{C}$. A. tumefaciens was grown at $28{ }^{\circ} \mathrm{C}$ in $2 \mathrm{YT}$ medium $(16 \mathrm{~g} / \mathrm{L}$ tryptone, $10 \mathrm{~g} / \mathrm{L}$ yeast extract, $5 \mathrm{~g} / \mathrm{L} \mathrm{NaCl}$ ). Kanamycin, ampicillin, hygromycin, cefotaxime and rifampicin were supplemented to the medium to a final concentration of $50 \mu \mathrm{g} / \mathrm{mL}, 100 \mu \mathrm{g} /$ $\mathrm{mL}, 100 \mu \mathrm{g} / \mathrm{mL}, 300 \mu \mathrm{g} / \mathrm{mL}$, and $25 \mu \mathrm{g} / \mathrm{mL}$, respectively. Strain information used in this study are listed in Table 1.

\section{Plasmid construction and yeast transformation}

Standard genetic manipulations were performed as previously described [35]. pKOCAR2 plasmid was used as the gene expression vector for yeast transformation [32]. The profile of the plasmid is shown in Additional file 1: Fig. S8. The plasmid contains a hygromycin selection cassette composed of a GPD1 promoter from Rhodotorula graminis, a codon optimized hpt gene and a Tsv 40 terminator. A GPD1 promoter from $R$. toruloides and a T35s terminator was located downstream of the hygromycin selection cassette, where the exogenous gene can insert between them. The homologous sequences of Car2 gene (Car2 $\mathrm{L}$ and Car2 $\mathrm{R}$ ) were located at both ends of the expression cassettes. The LB and RB sequences are the left and right border sequences of T-DNA, which can be identified by the virD complex in A. tumefaciens and transferred to $R$. toruloides through ATMT method.

The WS genes were codon optimized and synthesized by Nanjing GeneScript Biotech Co., Ltd (Nanjing, China). The optimized gene sequences and primers used in this study are listed in Additional file 1: Tables S2 and S4, respectively. To ligate these genes to PKOCAR2, the plasmid was firstly digested by EcoRV and NcoI, and then ligated with each of the DNA fragment by NEBuiler HiFi Assembly kit (New England Biolabs, USA), and finally yielded the recombinant plasmids p101, p102, p103, p104, and p105, respectively.

For enzyme engineering of AbWS, overlap-extension PCR was used for site-directed mutagenesis [36]. Two pairs of primer were designed to amplify the upstream and downstream DNA fragments, respectively. The modified nucleic base was contained in the primers. The mutated $A b W S$ gene was ligated to the pKOCAR2 plasmid, yielding recombinant plasmid p1022. All plasmids used in this study are listed in Table 1. 
The recombinant plasmids were transformed into $R$. toruloides by ATMT as described previously [37]. The pKOCAR2-derived plasmids were firstly electroporated into A. tumefaciens AGL-1. Then the A. tumefaciens strain harboring the corresponding plasmid was co-cultured with the $R$. toruloides $\Delta k u 70$, and the mixture was spread on YPD solid plate supplemented with hygromycin and cefotaxime for colony screening. Colonies appeared after 2 days.

\section{Fermentation conditions}

Shake-flask batch fermentation was conducted in a 50-ml Erlenmeyer flask containing $10 \mathrm{ml}$ of fermentation medium. The culture was inoculated with $10 \%$ seed culture, and performed in an orbital shaker at a rotary rate of $250 \mathrm{rpm}$ at $30{ }^{\circ} \mathrm{C}$. When the cell density reached around OD 2 (approximately 8-12 h after inoculation), exogenous ethanol was added to the culture to a final concentration of $1 \%, 3 \%, 5 \%, 7 \%$, respectively. To facilitate the extraction process, $10 \%$ dodecane was added to the culture as reported previously [15]. Ethyl heptadecanoic was used as the internal standard.

High-density fermentation was conducted in a 1-L stirred bioreactor (Eppendorf, Germany) with an initial volume of $500 \mathrm{~mL}$. The $\mathrm{pH}$ of the medium was monitored in real-time by a $\mathrm{pH}$ meter (Mettler-Toledo, Switzerland), and dissolved oxygen was monitored in real-time by an oxygen probe (Mettler-Toledo, Switzerland). The cultivation conditions were the same as what was previously described [21]. The inoculation volume was $50 \mathrm{~mL}$, and the dissolved oxygen was set at $50 \%$ with an airflow rate of $1.25 \mathrm{vvm}$. The $\mathrm{pH}$ was maintained at 5.6 using $4 \mathrm{M}$ $\mathrm{NaOH}$. For batch fermentation, the initial glucose concentration was $70 \mathrm{~g} / \mathrm{L}$ without feeding glucose during fermentation. For fed-batch fermentation, the initial glucose concentration was $70 \mathrm{~g} / \mathrm{L}$, and $50 \mathrm{~mL}$ glucose with a concentration of $500 \mathrm{~g} / \mathrm{L}$ was fed to the culture when glucose concentration was below $10 \mathrm{~g} / \mathrm{L} .50 \mathrm{~mL} 50 \%$ ethanol was pumped to the fermenter at a flow rate of $1 \mathrm{~mL} / \mathrm{min}$ to a final concentration of $5 \% .50 \mathrm{~mL}$ dodecane together with ethyl heptadecanoate (C17:0) internal standard were injected to the fermenter through a syringe.

\section{Analytical methods}

The growth curves of the $R$. toruloides strains were determined by measuring the cell density at $600 \mathrm{~nm}$ using a Genesys 20 spectrophotometer (Thermo Fischer Scientific Inc., USA). The dry cell weight (DCW) was determined by the previously described method [5]. The concentrations of glucose and ethanol were monitored by a LC-20A HPLC instrument (Shimadzu Inc., Japan) equipped with a RID detector as previously reported [15].

\section{Total lipids and FAEEs extraction and analysis}

For extracellular FAEEs, the concentration was determined by directly injecting the dodecane layer to a SHIMADZU Japan GCMS-QP2010 PLUS mass spectrometer coupled with a SHIMADZU gas chromatograph (Shimadzu Inc., Japan). The ethyl heptadecanoic was added to the medium as the internal standard. The FAEEs dissolved in the dodecane layer were separated using a SHIMADZU 5MS capillary column (30 $\mathrm{m} \times 0.25 \mathrm{~mm}$ I. D., $0.25 \mu \mathrm{m}$ film thickness) as previously described [38].

For intracellular FAEEs, the concentration was measured by the following procedure. First, the total lipids were extracted. Cells were harvested and washed twice with double-distilled water $\left(\mathrm{ddH}_{2} \mathrm{O}\right)$, and then freezedried until the samples were dry. Lipids were extracted from the lyophilized cells as previously reported [39]. Ethyl heptadecanoic was added as an internal standard. Second, lipids were separated and fractionated. FAEE components in the total lipid extracts were separated by thin layer chromatography using TLC Silica gel 60 F254 plates as previously reported [12] (Merck, Darmstadt, Germany). The FAEE components were then scraped from the TLC plate and extracted by an organic solvent containing $3 \mathrm{~mL}$ hexane, $2 \mathrm{~mL}$ metha-

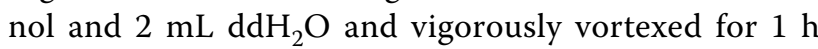
at room temperature. After centrifuging at $1676 \times g$ for $5 \mathrm{~min}$, the organic phase was transferred to a new glass tube and dried under nitrogen. The residues were dissolved in $200 \mu \mathrm{L}$ methanol: chloroform (95:5) for GCMS analysis.

To determine the fatty acid composition, total lipids were transmethylated and analyzed according to a previously reported method [40].

\section{WS assay}

The samples were harvested from batch cultures during the mid-exponential phase (at OD 3) for enzyme activity measurement. The cultures were washed twice by $1 \times$ phosphate buffer saline (PBS). Cell lysate was then prepared using a Fast Prep cell homogenizer (MP biomedicals, Solon, OH, USA). The proteins were quantified by a Bradford reagent (Sangon Biotech Co., Ltd. (Shanghai, China)). WS activity was determined by monitoring CoA release using Ellman's reagent [5,5-dithio-bis (2-nitrobenzoic acid); DTNB] at $412 \mathrm{~nm}$ [38]. In vitro assays were performed in triplicate in $250 \mu \mathrm{L}$ reaction system containing $125 \mathrm{mM}$ sodium phosphate buffer $(\mathrm{pH}$ 7.4), $1.45 \%$ dimethyl sulfoxide (DMSO), $1 \mathrm{mM}$ DNTB, $1 \mu \mathrm{M}$ palmitoyl-CoA, $10 \mathrm{mM}$ ethanol, and 10 ug of crude enzyme. Assay reactions were detected by a multimode plate reader (PerkinElmer Inc., USA). 


\section{Western blot}

The cells were sampled in the exponential growth period, and homogenized using a FastPrep instrument for 6 cycles at a speed of $6.0 \mathrm{~m} / \mathrm{s}$ for $30 \mathrm{~s}$ each, with $5 \mathrm{~min}$ of interval. The suspensions were centrifuged at $15,000 \mathrm{~g}$ for $30 \mathrm{~min}$, and the supernatants were collected [34]. Then the total proteins were detected by sodium dodecyl sulfate-polyacrylamide gel electrophoresis (SDS-PAGE) with $12 \%$ polyacrylamide gels, which were then immediately transferred to a polyvinylidene difluoride (PVDF) membrane (BIO-RAD, USA). A Flag tag was added in the $5^{\prime}$ end of the $A b W S$ gene. A monoclonal anti-FLAG M2 antibody was used for Western blot analysis as previously described [41], and the membrane was covered with electrochemiluminescence (ECL) plus solution for color reaction. Finally, the membrane was exposed to the Gel Imager System (Azure, USA) by the chemiluminescence mode.

\section{Abbreviations}

GC-MS: Gas chromatography-mass spectrometry; TAG: Triglycerides; HPLC: High-performance liquid chromatography; LB: Luria-Bertani; ATMT: A. tumefaciens-Mediated transformation; DCW: Dry cell weight; TLC: Thin layer chromatography; PVDF: Polyvinylidene difluoride.

\section{Supplementary Information}

The online version contains supplementary material available at https://doi. org/10.1186/s13068-021-01965-3.

Additional file 1. Additional tables and figures

\section{Acknowledgements}

The authors thank Prof. Zongbao K Zhao in the Dalian Institute of Chemical Physics (Dalian, China) and Prof. Lianghui Ji in the Temasek Life Sciences Laboratory (Singapore) for providing the strains used in this study.

\section{Authors' contributions}

SBS, HZ, and $Y Z$ designed the experiments. $Y Z$ and JP performed the experimental work. YZ analyzed the data and wrote the manuscript. $\mathrm{HZ}$ and SBS revised the manuscript. All authors read and approved the final manuscript.

\section{Funding}

This work was supported by National Natural Science Foundation of China (21878013 and 2191101491), National Key Research and Development Program of China (2018YFA0900100), the Foundation of Key Laboratory of Biomass Chemical Engineering of Ministry of Education, Zhejiang University (No. 2018BCE004), the Fundamental Research Funds for the Central Universities, and Beijing Advanced Innovation Center for Soft Matter Science and Engineering.

\section{Availability of data and materials}

All data generated or analyzed during this study are included in this published article and its additional files.

\section{Declarations}

Ethics approval and consent to participate Not applicable.

\section{Consent for publication}

All authors agree to submit the work to the journal.

\section{Competing interests}

The authors declare that they have no competing interest.

Received: 16 December 2020 Accepted: 1 March 2021

Published online: 08 May 2021

\section{References}

1. Ma F, Hanna M. Biodiesel production: a review. Bioresour Technol. 1999;70(1):1-15.

2. Hill J, Nelson E, Tilman D, Polasky S, Tiffany D. Environmental, economic, and energetic costs and benefits of biodiesel and ethanol biofuels. Proc Natl Acad Sci USA. 2006;103(30):11206-10.

3. Zheng M, Mulenga MC, Reader GT, Wang MP, Ting DSK, Tjong J. Biodiesel engine performance and emissions in low temperature combustion. Fuel. 2008:87(6):714-22.

4. Knothe G, Steidley KR. Lubricity of components of biodiesel and petrodiesel The origin of biodiesel lubricity. Energy Fuels. 2005;19(3):1192-200.

5. Kalscheuer R, Stolting T, Steinbuchel A. Microdiesel: Escherichia coli engineered for fuel production. Microbiol. 2006;152(9):2529-36.

6. Bhuiya M, Rasul M, Khan M, Ashwath N, Azad A. Prospects of 2nd generation biodiesel as a sustainable fuel_-Part: 1 selection of feedstocks, oil extraction techniques and conversion technologies. Renew Sust Energy Rev. 2016:45:1109-28.

7. Fukuda $\mathrm{H}$, Kondo A, Noda H. Biodiesel fuel production by transesterification of oils. J Biosci Bioeng. 2001;92(5):405-16.

8. Santori G, Nicola G, Moglie M, Polonara F. A review analyzing the industrial biodiesel production practice starting from vegetable oil refining. Appl Energy. 2012;92(4):109-32.

9. Du J, Shao ZY, Zhao HM. Engineering microbial factories for synthesis of value-added products. J Ind Microbiol Biotechnol. 2011:38(8):873-90.

10. Elbahloul Y, Steinbuchel A. Pilot-scale production of fatty acid ethyl esters by an engineered Escherichia coli strain harboring the p(Microdiesel) plasmid. Appl Environ Microbiol. 2010;76(13):4560-5.

11. Rottig A, Zurek P, Steinbuchel A. Assessment of bacterial acyltransferases for an efficient lipid production in metabolically engineered strains of $E$. coli. Metab Eng. 2015;32:195-206.

12. Shi S, Vallerodriguez J, Khoomrung S, Siewers V, Nielsen J. Functional expression and characterization of five wax ester synthases in Saccharomyces cerevisiae and their utility for biodiesel production. Biotechnol Biofuels. 2012;5(1):7-7.

13. Yu K, Jung J, Kim S, Park C, Han S. Synthesis of FAEEs from glycerol in engineered Saccharomyces cerevisiae using endogenously produced ethanol by heterologous expression of an unspecific bacterial acyltransferase. Biotechnol Bioeng. 2012;109(1):110-5.

14. Xu P, Qiao K, Ahn WS, Stephanopoulos G. Engineering Yarrowia lipolytica as a platform for synthesis of drop-in transportation fuels and oleochemicals. Proc Natl Acad Sci USA. 2016;113(39):10848-53.

15. Gao Q, Cao X, Huang Y, Yang J, Chen J, Wei L, Hua Q. Overproduction of fatty acid ethyl esters by the oleaginous yeast Yarrowia lipolytica through metabolic engineering and process optimization. ACS Synth Biol. 2018;7(5):1371-80.

16. Park Y, Nicaud J, Ledesmaamaro R. The engineering potential of Rhodosporidium toruloides as a workhorse for biotechnological applications. Trends Biotechnol. 2017;36(3):304-17.

17. Wen Z, Zhang S, Odoh CK, Jin M, Zhao ZK. Rhodosporidium toruloidesa potential red yeast chassis for lipids and beyond. FEMS Yeast Res. 2020;20(5):38

18. Zhang S, Skerker JM, Rutter CD, Maurer MJ, Arkin AP, Rao CV. Engineering Rhodosporidium toruloides for increased lipid production. Biotechnol Bioeng. 2016;113(5):1056-66.

19. Fatma Z, Schultz JC, Zhao HM. Recent advances in domesticating nonmodel microorganisms. Biotechnol Prog. 2020;36:5. 
20. Jin G, Zhang Y, Shen H, Yang X, Xie H, Zhao ZK. Fatty acid ethyl esters production in aqueous phase by the oleaginous yeast Rhodosporidium toruloides. Bioresour Technol. 2013;150:266-70.

21. Li Y, Zhao ZK, Bai F. High-density cultivation of oleaginous yeast Rhodosporidium toruloides $Y 4$ in fed-batch culture. Enzyme Microb Technol. 2007;41(3):312-7.

22. Barney BM, Mann R, Ohlert JM. Identification of a residue affecting fatty alcohol selectivity in wax ester synthase. Appl Environ Microbiol. 2013:79(1):396-9.

23. Villa JA, Cabezas M, De IC, F., Moncalian G. Use of Limited Proteolysis and Mutagenesis To Identify Folding Domains and Sequence Motifs Critical for Wax Ester Synthase/Acyl Coenzyme A:Diacylglycerol Acyltransferase Activity. Appl Environ Microbiol. 2014; 80(3):1132-1141.

24. Soccol C, Neto C, Soccol V, Sydney E, Vandenberghe L. Pilot scale biodiesel production from microbial oil of Rhodosporidium toruloides DEBB 5533 using sugarcane juice: Performance in diesel engine and preliminary economic study. Bioresour Technol. 2017;223:259-68.

25. Marella ER, Holkenbrink C, Siewers V, Borodina I. Engineering microbial fatty acid metabolism for biofuels and biochemicals. Curr Opin Biotechnol. 2018:50:39-46.

26. Hu Y, Zhu Z, Nielsen J, Siewers V. Heterologous transporter expression for improved fatty alcohol secretion in yeast. Metab Eng. 2017:S1096717617302951.

27. Vallerodriguez J, Shi S, Siewers V, Nielsen J. Metabolic engineering of Saccharomyces cerevisiae for production of fatty acid ethyl esters, an advanced biofuel, by eliminating non-essential fatty acid utilization pathways. Appl Energy. 2014;115(4):226-32.

28. Zhu Z, Zhang S, Liu H, Shen H, Lin X, Yang F, Zhou Y, Jin G, Ye M, Zou H. A multi-omic map of the lipid-producing yeast Rhodosporidium toruloides. Nat Commun. 2012;3(1):1112-1112.

29. Lee J, Chi W, Hong S, Yang J, Chang Y. Bioethanol production by heterologous expression of Pdc and Adhll in Streptomyces lividans. Appl Microbiol Biotechnol. 2013;97(13):6089-97.

30. Drewke C, Ciriacy M. Overexpression, purification and properties of alcohol dehydrogenase IV from Saccharomyces cerevisiae. Gene Struct Expression. 1988;950(1):54-60.

31. Yu A, Zhao Y, Li J, Li S, Xiao D. Sustainable production of FAEE biodiesel using the oleaginous yeast Yarrowia lipolytica. MicrobiologyOpen. 2020; $9: 2$
32. Koh C Liu Y, Du Moehninsi, M, Ji L. Molecular characterization of KU70 and KU80 homologues and exploitation of a KU70-deficient mutant for improving gene deletion frequency in Rhodosporidium toruloides. BMC Microbiol. 2014;14(1):50-50

33. Zhu Z, Ding Y, Gong Z, Yang L, Zhang S, Zhang C, Lin X, Shen H, Zou H, Xie $Z$, et al. Dynamics of the lipid droplet proteome of the oleaginous yeast Rhodosporidium toruloides. Eukaryot Cell. 2015:14(3):252-64.

34. Liu Y, Koh C, Ngoh S, Ji L. Engineering an efficient and tight d-amino acid-inducible gene expression system in Rhodosporidium/ Rhodotorula species. Microb Cell Fact. 2015;14(1):170-170.

35. Wood E. Molecular Cloning. A Laboratory Manual. Biochem Educ. 1983;11(2):82

36. Xiao YH, Yin MH, Hou L, Luo M, Pei Y. Asymmetric overlap extension PCR method bypassing intermediate purification and the amplification of wild-type template in site-directed mutagenesis. Biotech Lett. 2007;29(6):925-30

37. Lin $X$, Wang $Y$, Zhang S, Zhu Z, Zhou Y, Yang F, Sun W, Wang $X$, Zhao Z. Functional integration of multiple genes into the genome of the oleaginous yeast Rhodosporidium toruloides. Fems Yeast Res. 2014;14(4):547-55.

38. Holtzapple E, Schmidtdannert C. Biosynthesis of Isoprenoid Wax Ester in Marinobacter hydrocarbonoclasticus DSM 8798: Identification and Characterization of Isoprenoid Coenzyme A Synthetase and Wax Ester Synthases. J Bacteriol. 2007;189(10):3804-12.

39. Gu Z, Valianpour F, Chen S, Vaz F, Hakkaart G, Wanders R, Greenberg M. Aberrant cardiolipin metabolism in the yeast taz1 mutant: a model for Barth syndrome. Mol Microbiol. 2003;51(1):149-58.

40. Ferreira R, Teixeira P, Siewers V, Nielsen J. Redirection of lipid flux toward phospholipids in yeast increases fatty acid turnover and secretion. Proc Natl Acad Sci USA. 2018;115(6):1262-7.

41. Kaishima M, Ishii J, Matsuno T, Fukuda N, Kondo A. Expression of varied GFPs in Saccharomyces cerevisiae: codon optimization yields stronger than expected expression and fluorescence intensity. Sci Rep. 2016:6(1):35932.

\section{Publisher's Note}

Springer Nature remains neutral with regard to jurisdictional claims in published maps and institutional affiliations.
Ready to submit your research? Choose BMC and benefit from:

- fast, convenient online submission

- thorough peer review by experienced researchers in your field

- rapid publication on acceptance

- support for research data, including large and complex data types

- gold Open Access which fosters wider collaboration and increased citations

- maximum visibility for your research: over $100 \mathrm{M}$ website views per year

At BMC, research is always in progress.

Learn more biomedcentral.com/submissions 